\title{
Contemporary literature from China: new voices and discourses
}

\author{
Jiangkai Liu'
}

Published online: 9 March 2019

(C) Academy for International Communication of Chinese Culture 2019

(Translated by Xuemei Shi)

The heralds of spring 2019 have arrived and a new life cycle begins.

It is the rejuvenation of all things that makes the world last indefinitely (Luo 2011). As part of the objective existence of 'all things', China, with its long history, and the world transcend and transform ceaselessly moving towards a renewed ecological civilization.

The material world lasts forever and the spiritual world is immortal. They have their immanent modes of existence and their transforming and renewed forms as well. Regarding our ways of beholding the relationship between humans and things, the prevailing paradigm has long been 'man-and-thing', while today the field of Material Ecology offers a new perspective: 'man-as-thing'.

In the 650 line long poem Roaming the Fuchun Mountain with Huang Gongwang, the poet Zhai Yongming travels back and forth in time. She connects real spaces with the timespace of the painting to encompass nature, art, life, and the society that are all woven into a magnificent 'landscape' (Zhai 2015).

China's long history unfolds before our eyes like a horizontal scroll painting. When we travel through the landscapes of this long handscroll we encounter the numerous splendid views known from Chinese history: we listen to ancient myths and stories from the Spring and Autumn and Warring States Periods, we pass by the Great Wall built by the Qin and Han Dynasties, we appreciate the poetry of Tang and Song Dynasties, we are awed by the prosperity visible in the famous painting Along the River during the Qingming Festival, and we finally witness the celebration

Jiangkai Liu

ljk@bnu.edu.cn

1 Academy for International Communication of Chinese Culture, Beijing Normal University, 1732, New Main Building, 19 Xinjiekou Wai Street, Beijing 100875, China 
of the 70th anniversary of the People's Republic of China. We cannot help wondering what new 'landscapes' can contemporary Chinese literature add to the grand 'scroll painting' that depicts Chinese history?

The earth is the mother of all things, all things generate civilizations, and civilizations nurture all things and the earth by return. When we apply the concept of 'manas-thing' (人以物) to examine 'men and things' (人与物), we may gain new insights into the relationship between the human and the world. This new understanding may eventually help us to bring viable solutions to the ecological crisis.

By the same token, any description of the complex relationship between men, countries, nations, or between civilizations should not be oversimplified and reduced to the 'we versus they' (他者) dynamics; rather, it should be modeled on the ancient Chinese philosophical concept of 'heaven and human merging into one' (天人合一). If man is no longer regarded the master and owner of all things but is rather seen as their equal, human beings will coexist in a more harmonious way (和 合) with 'other' things (Chen (nd)).

Hence China and the world draw on each other's experiences and strengths on the one hand and exist as an integral unity on the other. Translation resembles a traveller and makes it possible for literatures from various localities to tell their distinctive stories and converse with the world. When we engage into a dialogue between local literatures and transnational perspectives we often discover fresh cultural 'landscapes' that are entirely different from stereotypical impressions and enable us a more inclusive, transgressive understanding of global literature.

The ever-changing nature of all things gives rise to young generations that will add new strengths and ideas to intellectual discourses. These newcomers stand for independence and open-mindedness, confidence and tolerance, but they also remain connected with their predecessors, peers, as well as overseas counterparts. China and the world should listen to their voices, and, if we listen carefully enough, we will hear those young powerful voices speaking across the aged land of China.

It is the existence of these different voices that makes cultural exchange so engaging and valuable. Aiming at the facilitation and promotion of the dialogue on contemporary Chinese literature, this issue compiles the following papers. Jiangkai Liu's paper focuses on Mo Yan's latest works and discusses literary imagination and configuration of contemporary Chinese literature from a global perspective; Haitian Yan's paper discusses entanglements between traditional and contemporary novels in the light of a renaissance of the 'Zi collection'; Kun Zhao's paper analyzes the emergence of genderless identities and the 'avoidance of reproduction issues' in the literature of the Great Leap Forward; Yunxia Chu's paper offers a fresh interpretation of so-called Red narratives from the perspective of Buddhist rhetoric; Shiyu Liu's paper proposes an in-depth study of the figure of Liang Shengbao, who embodies the ideal of a 'new socialist man' in the novel entitled Builders of a New Life. (《创业史》)

In addition to novels, this issue also includes papers on contemporary poetry and films. Qiang Feng reinterprets 'qi', a key word in traditional Chinese poetry, in the context of contemporary Chinese poetry; Haibin Zhang comments on a new collection of poems by the famous Chinese scholar Qinghua Zhang; Andrea Riemenschnitter traces elements of Material Ecology in Yu Jian's poetry and Justyna 
Jaguścik analyzes Zhai Yongming's long poem Roaming the Fuchun Mountain with Huang Gongwang. All papers contribute to the dialogue on contemporary Chinese poetry. Besides, Huiquan Tian's paper on contemporary Chinese film grants fresh insights into contemporary Chinese culture.

Overseas and Chinese scholars voice their views on contemporary Chinese poetry, novels and films. Their papers range from macro-level literary observations to detailed close readings or reinterpretation of old questions. They add new approaches to the discourse of contemporary Chinese literature. As a Chinese proverb goes: Spring foretells the success of a year as the dawn for a day, so let's listen to those vibrating voices that shape the future in the time when all things bloom.

\section{References}

Chen, Tongsheng. Discourses of the States (Guoyu) (trans.). Beijing: Zhonghua Book Company Press.

Luo, Han. 2011. On Regeneration. In A Dictionary of Appreciation of Hundreds of Famous Texts by Scholars of Thought. Shanghai: Shanghai Dictionary (Cishu) Press.

Zhai, Yongming. 2015. Roaming the Fuchun Mountain with Huang Gongwang. Beijing: CITIC Press Group. 